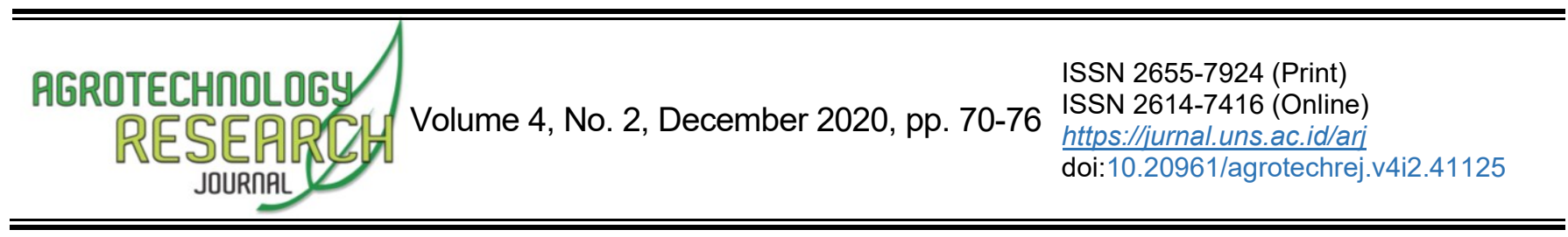

\title{
Peran Vermikompos terhadap Morfofisiologi Kangkung Hidroganik
}

\author{
A. R. Darmawan Putra ${ }^{1}$, Siti Asmaniyah Mardiyani ${ }^{2}$, Nurhidayati $^{*}$ \\ ${ }^{1-3}$ Department of Agrotechnology, Faculty of Agriculture, Universitas Islam Malang, Malang, Indonesia
}

Received 11 April 2020; Accepted 1 July 2020; Published 1 December 2020

\begin{abstract}
Since open-field agriculture will face some severe problems in the near future like availability of land and agricultural productivity, an alternative cultivation system, such as soilless cultivation is needed for the sustainability of supply and demand for healthier and safer food. This study aimed to test the effect of vermicompost application method and dosage on growth, yield, and chlorophyll content of water spinach. This experiment used a factorial randomized block design with controls. The first factor was the vermicompost application method, which consisted of three levels, namely solid vermicompost, the combination of solid and liquid vermicompost, liquid vermicompost. The second factor was the vermicompost dosage, which consisted of five levels: 100, 200, 300, 400, and 500g per polybag, compared with control using inorganic fertilizer. The results showed that the vermicompost application method did not significantly affect plant growth and yield. The dosage of $500 \mathrm{~g}$ in the three different application methods gave significantly higher plant growth compared to control. The fresh weight of water spinach per plant and per polybag in the dosage of $500 \mathrm{~g}$ showed the highest yield of $13.95 \mathrm{~g}$ and $122.17 \mathrm{~g}$, respectively. The highest chlorophyll content of water spinach was found in solid vermicompost treatment with an application rate of $500 \mathrm{~g}$, namely $30.10 \mu \mathrm{g} / \mathrm{ml}$ (chlorophyll A) and $54.79 \mu \mathrm{g} / \mathrm{ml}$ (chlorophyll B). These results indicate that to produce high-quality water spinach in soilless culture systems, it is recommended to use solid vermicompost with an application rate of $500 \mathrm{~g}$ per polybag.
\end{abstract}

Keywords: Soil-less culture; Organic fertilizer; Yield; Quality

Cite This As (CSE Style): Putra ARD, Mardiyani SA, Nurhidayati. 2020. Peran Vermikompos terhadap Morfofisiologi Kangkung Hidroganik. Agrotech Res J. 4(2): 70-76. https://doi.org/10.20961/agrotechresj.v4i2.41125

\section{PENDAHULUAN}

Kebutuhan sayuran dari waktu ke waktu semakin meningkat dengan semakin meningkatnya kesadaran masyarakat untuk hidup sehat dengan mengonsumsi pangan fungsional yang memiliki peran penting untuk meningkatkan kesehatan masyarakat. Hal ini dibuktikan bahwa pada periode 2000-2010 terjadi defisit perdagangan total sayuran. Kondisi ini mengindikasikan bahwa produksi nasional tidak mampu memenuhi kebutuhan pasar di dalam negeri sehingga sebagian kebutuhan pasar dalam negeri harus dipenuhi melalui impor. Defisit kuantitas perdagangan total sayuran pada periode 2000-2010 mencapai 346 juta ton per tahun (Data diolah dari Statistik FAO oleh Irawan dan Ariningsih 2014). Oleh karena itu diperlukan upaya peningkatan produksi sayuran untuk memenuhi kebutuhan pasar dalam negeri.

Salah satu tanaman sayuran daun (leafy vegetables) yang sering dikonsumsi oleh masyarakat adalah kangkung. Kangkung memiliki kandungan gizi tinggi seperti kalori, protein, lemak, karbohidrat, serat, kalsium,

*Corresponding Author:

E-Mail: nurhidayati@unisma.ac.id fosfor, zat besi, natrium, kalium, vitamin A, vitamin B, vitamin C, karoten, hentriakontan, dan sitosterol. Senyawa kimia yang dikandung adalah saponin, flavonoid, dan poliferol (Pracaya 2009).

Di sisi lain, ketersediaan lahan pertanian saat ini semakin berkurang akibat konversi lahan yang semakin meluas. Untuk menjamin ketersediaan pangan yang berkelanjutan diperlukan teknik budidaya alternatif yang dapat meningkatkan produksi tanaman secara kontinu yaitu dengan menerapkan sistem budidaya tanpa tanah salah satunya adalah hidroponik (Khan 2018). Hidroponik adalah alternatif bercocok tanam tanpa menggunakan media tanah melainkan dapat menggunakan air atau bahan porous seperti kerikil, pecahan genteng, arang sekam, pasir, dan batu bata. Bertanam secara hidroponik dapat berkembang secara cepat karena memiliki kelebihan antara lain keberhasilan tanaman untuk tumbuh, jarak tanam bisa lebih rapat, ketersediaan nutrisi dapat terkontrol, sehingga produktivitasnya lebih tinggi daripada sistem konvensional (Lingga 2006; Sengupta dan Banerjee 2012). Dari aspek kualitas, tanaman sayuran yang dibudidayakan secara hidroponik lebih higienis dan terkontrol serta tidak menggunakan pestisida kimia (Bulgari et al. 2017; Sharma et al. 2018). Namun disisi lain, sistem hidroponik membutuhkan sistem rancangan penanaman yang spesifik dan teknologi tinggi dan 
modern, sehingga membutuhkan biaya yang cukup besar (Sengupta dan Banerjee 2012; Sharma et al. 2018). Oleh karena itu perlu sistem budidaya hidroponik alternatif yang memanfaatkan media organik dan pupuk organik yang dikenal dengan hidroganik. Pada penelitian ini menggunakan sabut kelapa dan biochar serta vermikompos sebagai sumber nutrisinya, Sabut kelapa banyak digunakan dalam sistem hidroponik, karena bersifat ramah lingkungan serta memiliki daya serap air yang tinggi (Sani 2015). Biochar merupakan hasil proses pirolisis bahan organik dengan $\mathrm{C} / \mathrm{N}$ rasio tinggi yang mengandung $\mathrm{C}$ organik tinggi dan mampu menjerap unsur hara (Liang et al. 2006; Biederman dan Harpole 2013).

Vermikompos adalah pupuk organik yang memiliki unsur hara tinggi karena dalam vermikompos mengandung kotoran cacing. Keunggulan vermikompos adalah menyediakan $\mathrm{N}, \mathrm{P}, \mathrm{K}, \mathrm{Ca}$ dan $\mathrm{Mg}$ yang tersedia dalam jumlah yang seimbang dan meningkatkan kandungan bahan organik, meningkatkan kemampuan tanah, menyediakan hormon pertumbuhan tanaman serta sebagai penyangga pengaruh negatif (Lazcano dan Domínguez 2011). Selain itu aplikasi vermikompos menggunakan media tanah dan kotoran sapi mampu meningkatkan kualitas tanaman kubis (Nurhidayati et al. 2016). Pada percobaan di lahan pertanian aplikasi vermikompos meningkatkan pertumbuhan dan hasil tanaman brokoli (Nurhidayati et al. 2017a) serta memberikan efek residu positif pada tanaman berikutnya (Nurhidayati et al. 2017b; Nurhidayati et al. 2018). Aplikasi vermikompos 20 ton/ha yang dikombinasikan dengan pupuk semprot mampu meningkatkan hasil tanaman Cucurbita (Labu) (Razzaghifard et al. 2017).

Sedikit sekali yang mencoba mengaplikasikan vermikompos pada budidaya tanpa tanah atau hidroponik yang menggunakan substrat padat. Oleh karena itu perlu dilakukan penelitian tentang aplikasi vermikompos pada media tanam tanpa tanah sebagai sistem budidaya hidroganik untuk meningkatkan hasil dan kualitas tanaman kangkung.

Tujuan penelitian ini adalah untuk menjelaskan pengaruh beberapa metode dan dosis aplikasi vermikompos terhadap pertumbuhan, hasil dan kandungan klorofil tanaman kangkung yang ditanam dengan sistem hidroganik.

\section{BAHAN DAN METODE}

Penelitian ini dilakukan di Rumah Kaca di jalan MT. Haryono no. 198, Kelurahan Dinoyo, Kecamatan Lowokwaru Kota Malang dengan ketinggian tempat kurang lebih 550 meter di atas permukaan laut, suhu rata-rata harian sekitar $23^{\circ} \mathrm{C}$ sampai dengan $30^{\circ} \mathrm{C}$. Pembuatan vermikompos dilakukan di Laboratorium kompos Fakultas Pertanian UNISMA Penelitian dilakukan pada bulan Agustus-Desember 2019.

Bahan yang digunakan dalam penelitian adalah kotoran sapi, cacing (Lumbricus rubellus), sisa sayuran pasar, seresah daun, cocopeat, tepung tulang ikan, daun paitan, tepung cangkang telur, arang sekam, pasir, EM4, molase, bekas media jamur, air dan benih kangkung (Ipomoea reptans Poir). Alat-alat yang digunakan dalam proses pembuatan vermikompos adalah kotak vermicomposting, termometer, dan kontainer ukuran 45 liter).

Percobaan menggunakan Rancangan Acak Kelompok Faktorial (RAK) dengan Kontrol. Faktor I adalah metode aplikasi vermikompos terdiri dari tiga taraf yaitu $\mathrm{M} 1=$ vermikompos padat, $\mathrm{M} 2=$ kombinasi vermikompos padat dan cair, M3 = vermikompos cair. Faktor II adalah Dosis vermikompos yang terdiri dari lima taraf yaitu V1= $100 \mathrm{~g} /$ polibag, V2= $200 \mathrm{~g} /$ polibag, V3= $300 \mathrm{~g} /$ polibag, V4= $400 \mathrm{~g} /$ polibag dan V5= $500 \mathrm{~g} /$ polibag, ditambah satu perlakuan kontrol dengan menggunakan pupuk anorganik. Tiap kombinasi perlakuan diulang tiga kali dan masing-masing ulangan menggunakan tiga polibag sampel yang berisi 12 tanaman.

Pembuatan vermikompos dilaksanakan di laboratorium kompos. pembuatan vermikompos menggunakan kotak kayu berukuran $80 \times 120 \mathrm{~cm}$ dan tinggi $30 \mathrm{~cm}$. Tahapan pembuatan vermikompos meliputi : Persiapan residu pencampuran media, inokulasi cacing Lumbricus rubellus, dan pemeliharaan media cacing pada kondisi kadar air $80 \%$. Proses pembuatan vermikompos terdiri dari dua proses yaitu vermicomposting selama 1 bulan dan composting selama 2 minggu. Aplikasi vermikompos pada media tanam sesuai dengan perlakuan yang telah ditetapkan pada faktor I. Untuk yang menggunakan vermikompos padat diaplikasikan 1 minggu sebelum tanam. Vermikompos cair dibuat selama 1 minggu dan setelah itu siap diaplikasikan dengan cara disemprotkan pada media tanam dan tanaman setelah tanaman berumur 1 minggu setelah tanam. Kangkung ditanam secara langsung pada media tanam dalam polibag tanpa persemaian terlebih dahulu. Setiap polibag ditanam 12 benih kangkung. Pemanenan dilakukan pada umur 28 hari setelah tanam.

Variabel yang diamati terdiri dari tinggi tanaman $(\mathrm{cm})$, jumlah daun (helai), bobot per tanaman ( $\mathrm{g}$ ), bobot per polibag (g) dan kandungan klorofil $(\mu \mathrm{g} / \mathrm{ml})$ dengan metode (Wintermans dan De Mots 1965). Data yang telah diperoleh kemudian diuji dengan menggunakan analisis ragam atau uji $\mathrm{F}$ dengan taraf nyata $5 \%$, apabila hasil analisis menujukan pengaruh nyata, maka kemudian dilanjutkan uji lanjut BNJ dengan taraf $5 \%$ untuk membandingkan antar perlakuan dan diuji Dunnet $5 \%$ untuk membandingkan antara perlakuan dengan kontrol.

\section{HASIL DAN PEMBAHASAN}

Hasil analisis ragam menunjukkan tidak ada pengaruh interaksi nyata antara perlakuan metode dan dosis aplikasi vermikompos terhadap pertumbuhan tanaman kangkung pada umur 26 HST. Secara terpisah macam metode aplikasi vermikompos tidak memberikan pengaruh yang nyata, sedangkan dosis aplikasi vermikompos memberikan pengaruh yang nyata. Hasil uji BNJ 5\% kedua faktor disajikan pada Tabel 1. 
Tabel 1. Pengaruh dosis aplikasi vermikompos terhadap pertumbuhan tanaman kangkung pada umur 26HST

\begin{tabular}{lll}
\hline $\begin{array}{l}\text { Dosis } \\
\text { Vermikompos } \\
\text { (g/polibag) }\end{array}$ & $\begin{array}{l}\text { Tinggi Tanaman } \\
(\mathrm{cm})\end{array}$ & $\begin{array}{l}\text { Jumlah Daun } \\
\text { (helai) }\end{array}$ \\
\hline 100 & $24,54 \mathrm{a}$ & $6,54 \mathrm{a}$ \\
200 & $26,59 \mathrm{ab}$ & $6,89 \mathrm{ab}$ \\
300 & $27,18 \mathrm{ab}$ & $7,09 \mathrm{~b}$ \\
400 & $28,06 \mathrm{~b}$ & $7,20 \mathrm{~b}$ \\
500 & $30,44 \mathrm{~b}$ & $7,77 \mathrm{c}$ \\
\hline BNJ 5\% & 2,66 & 0,42 \\
\hline
\end{tabular}

Keterangan: angka diikuti oleh huruf yang sama di kolom yang sama tidak menunjukkan perbedaan yang signifikan dalam uji BNJ $5 \%$. BNJ = Nilai Beda Nyata Jujur

Tabel 1 menunjukkan bahwa semakin tinggi dosis aplikasi vermikompos, semakin tinggi tingkat pertumbuhan tanaman kangkung. Namun dosis aplikasi $200 \mathrm{~g} /$ polibag tidak berbeda nyata dengan dosis 300 , 400 dan $500 \mathrm{~g} /$ polibag untuk tinggi tanaman. Untuk parameter jumlah daun, pertumbuhan tertinggi dicapai pada dosis $500 \mathrm{~g} /$ polibag. Pertumbuhan tanaman dalam sistem hidroponik sangat tergantung pada suplai nutrisi yang diberikan ke dalam media (Resh 2012; Bulgari et al. 2017). Peningkatan respon tanaman pada dosis yang lebih tinggi menunjukkan bahwa asupan hara pada dosis yang lebih rendah belum mencukupi kebutuhan hara tanaman. Vermikompos mengandung unsur-unsur hara makro dan mikro seperti : Nitrogen $(\mathrm{N})$, Fosfor $(\mathrm{P})$, Kalium (K), Carbon (C), Seng (Zn), Mangan (Mn) dan Tembaga $(\mathrm{Cu})$, serta mengandung hormon yang dibutuhkan oleh tumbuhan untuk pertumbuhan seperti auksin, giberelin dan sitokinin (Marsono dan Sigit 2001). Aplikasi vermikompos mampu meningkatkan pertumbuhan beberapa jenis tanaman sayuran (Nurhidayati et al. 2015; Nurhidayati et al. 2016; Nurhidayati et al. 2017a). Vermikompos termasuk pupuk organik yang melepaskan unsur hara secara bertahap (slow release), sehingga meningkatkan sinkronisasi ketersediaan hara dengan serapan hara tanaman selama pertumbuhan tanaman dan meningkatkan efisiensi penggunaan pupuk dalam budidaya hidroganik (Singh et al. 2001; Kaushik dan Garg 2003).

Hasil uji Dunnet 5\% (Tabel 2) menunjukkan bahwa beberapa kombinasi perlakuan metode dan dosis aplikasi vermikompos memberikan rata-rata tinggi tanaman yang lebih rendah daripada kontrol. Tinggi tanaman pada perlakuan aplikasi vermikompos padat dengan dosis $400 \mathrm{~g}$ dan $500 \mathrm{~g}$ per polibag, aplikasi kombinasi vermikompos padat dan cair dengan dosis $200,300,400$, dan $500 \mathrm{~g}$ per polibag dan aplikasi vermikompos cair dengan dosis 300,400 , dan $500 \mathrm{~g}$ per polibag tidak berbeda nyata dengan kontrol pada umur 26 hst. Demikian juga pada jumlah daun tanaman dimana beberapa perlakuan memberikan jumlah daun sama dengan kontrol, dan lebih kecil dari kontrol.
Perlakuan aplikasi vermikompos padat, kombinasi vermikompos padat dan cair dan vermikompos cair dengan dosis $500 \mathrm{~g}$ per polibag memberikan jumlah daun yang lebih banyak secara signifikan $(P<0,05)$ dibandingkan kontrol.

Tabel 2. Hasil uji Dunnet $5 \%$ rata-rata tinggi tanaman dan jumlah daun pada kombinasi perlakuan metode dan dosis aplikasi vermikompos dibandingkan dengan kontrol

\begin{tabular}{|c|c|c|c|}
\hline \multicolumn{2}{|c|}{ Perlakuan } & \multirow{2}{*}{$\begin{array}{l}\text { Tinggi } \\
\text { Tanaman } \\
(\mathrm{cm})\end{array}$} & \multirow{2}{*}{$\begin{array}{l}\text { Jumlah } \\
\text { Daun } \\
\text { (helai) }\end{array}$} \\
\hline $\begin{array}{l}\text { Metode aplikasi } \\
\text { Vermikompos }\end{array}$ & $\begin{array}{l}\text { Dosis } \\
\text { (g/polibag) }\end{array}$ & & \\
\hline Kontrol & & 28,93 & 7,30 \\
\hline \multirow{5}{*}{ Padat } & 100 & $24,69^{\#}$ & $6,63^{\#}$ \\
\hline & 200 & $25,64 \#$ & $7,04^{\mathrm{tn}}$ \\
\hline & 300 & $26,09 \#$ & $7,15^{\mathrm{tn}}$ \\
\hline & 400 & $28,63^{\text {tn }}$ & $7,26^{\mathrm{tn}}$ \\
\hline & 500 & $29,77^{\text {tn }}$ & $7,67^{*}$ \\
\hline \multirow{5}{*}{$\begin{array}{l}\text { Padat dan } \\
\text { Cair }\end{array}$} & 100 & $25,85^{\#}$ & $6,37^{\#}$ \\
\hline & 200 & $27,72^{\text {tn }}$ & $6,70^{\#}$ \\
\hline & 300 & $28,45^{\text {tn }}$ & $6,89 \#$ \\
\hline & 400 & 28,50 tn & $7,15^{\mathrm{tn}}$ \\
\hline & 500 & $30,71^{\text {tn }}$ & 7,89 * \\
\hline \multirow{5}{*}{ Cair } & 100 & $23,09 \#$ & $6,63^{\#}$ \\
\hline & 200 & $26,41 \#$ & $6,93^{\#}$ \\
\hline & 300 & 27,01 tn & $7,22^{\mathrm{tn}}$ \\
\hline & 400 & $27,05^{\text {tn }}$ & $7,19^{\mathrm{tn}}$ \\
\hline & 500 & $30,84^{\text {tn }}$ & $7,74^{*}$ \\
\hline Dunnet 5\% & & 2,14 & 0,34 \\
\hline
\end{tabular}

Keterangan: tanda * menunjukkan berbeda nyata dengan kontrol, tanda \# menunjukkan berbeda nyata lebih kecil dari kontrol, tn menunjukkan tidak berbeda nyata dengan kontrol.

Hasil penelitian ini menunjukkan penggunaan pupuk organik pada budidaya tanpa tanah, memberikan pertumbuhan yang sama, bahkan bisa lebih tinggi dibandingkan dengan penggunaan pupuk anorganik (Tabel 2). Vermikompos memiliki keunggulan mampu menyediakan $\mathrm{N}, \mathrm{P}, \mathrm{K}, \mathrm{Ca}$ dan $\mathrm{Mg}$ yang tersedia, meningkatkan kandungan bahan organik, meningkatkan kemampuan tanah, menyediakan hormon pertumbuhan tanaman serta sebagai penyangga (Lazcano dan Domínguez 2011). Dari aspek kesehatan lingkungan, penggunaan pupuk organik lebih disarankan karena bebas dari produk bahan kimia sintetis sehingga menghasilkan produk pangan yang lebih sehat (Nurhidayati et al. 2018).

Hasil analisis ragam menunjukkan bahwa tidak ada pengaruh interaksi nyata antara perlakuan metode dan dosis aplikasi vermikompos terhadap hasil tanaman kangkung. Secara terpisah metode aplikasi vermikompos tidak memberikan pengaruh yang nyata terhadap hasil tanaman kangkung, sedangkan dosis aplikasi vermikompos memberikan perbedaan yang nyata terhadap hasil tanaman kangkung (Gambar 1 dan Gambar 2). 
Gambar 1 dan Gambar 2 menunjukkan bahwa semakin tinggi dosis aplikasi vermikompos semakin tinggi bobot segar kangkung yang dihasilkan, dimana dosis aplikasi yang memberikan hasil tertinggi secara signifikan pada $\mathrm{P}<0,05$ adalah dosis $500 \mathrm{~g} /$ polibag. Hal ini menunjukkan bahwa tanaman kangkung, masih memberikan respon positif terhadap peningkatan dosis aplikasi vermikompos. Hal ini berarti pembentukan jaringan sel-sel tanaman terus meningkat. Aplikasi vermikompos dapat memperbaiki sifat fisik, kimia dan media tumbuh, sehingga pertumbuhan tanaman menjadi lebih baik dan hasil tanaman meningkat (Lazcano et al. 2009). Pengaruh yang menguntungkan bila vermikompos diaplikasikan pada media tanam tanpa tanah yang mengandung cocopeat adalah terjadinya peningkatan berat dari media tanam dan menurunkan total porositas sehingga air mudah tersedia di dalam media tanam (Papafotiou et al. 2005; Bachman dan Metzger 2007; Grigatti et al. 2007).

Vermikompos memiliki luas permukaan partikel yang besar yang dapat memberikan ruang pori mikro untuk aktivitas mikrobia, mengikat unsur hara, kandungan hara yang tinggi dan populasi mikroorganisme yang tinggi sehingga dapat mengurangi porositas media hidroganik (Atiyeh et al. 2000). Perbaikan kondisi media tanam ini mampu memperbaiki pertumbuhan tanaman, hasil dan kualitas hasil tanaman pakcoy (Pant et al. 2011).

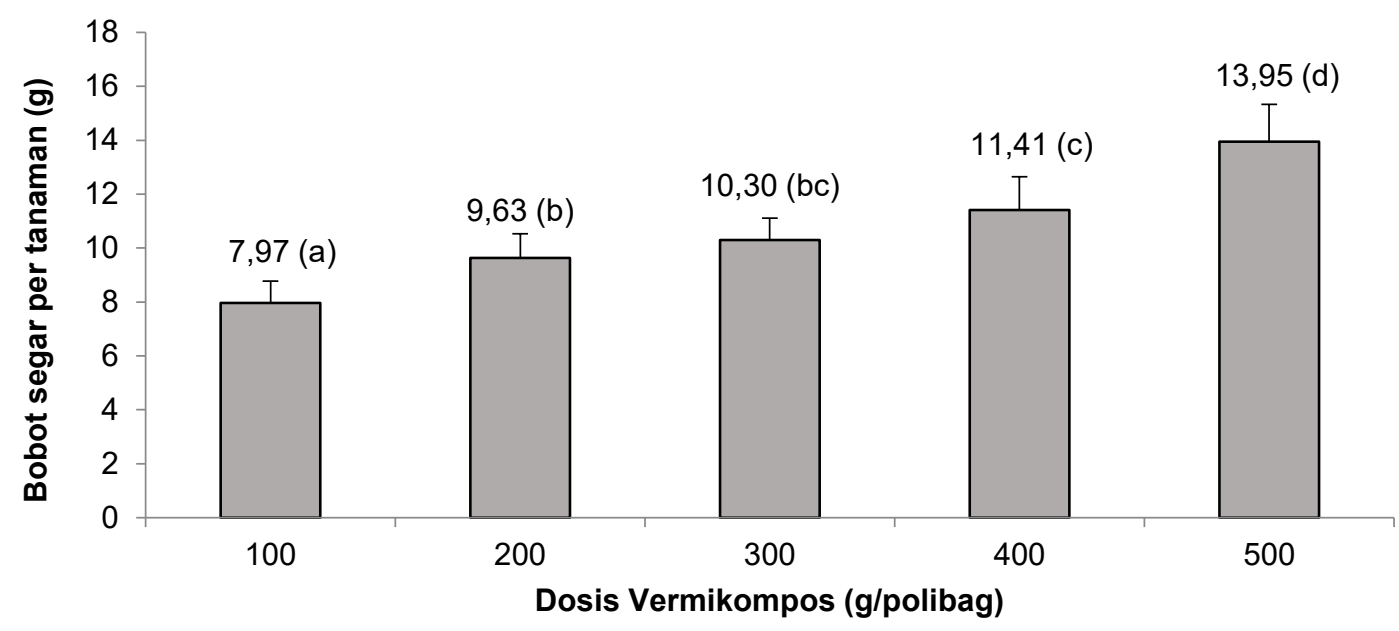

Gambar 1. Pengaruh dosis aplikasi vermikompos terhadap berat segar kangkung per tanaman (g) (Angka yang diikuti dengan huruf yang sama menunjukkan tidak berbeda nyata pada uji BNJ $5 \%$ )

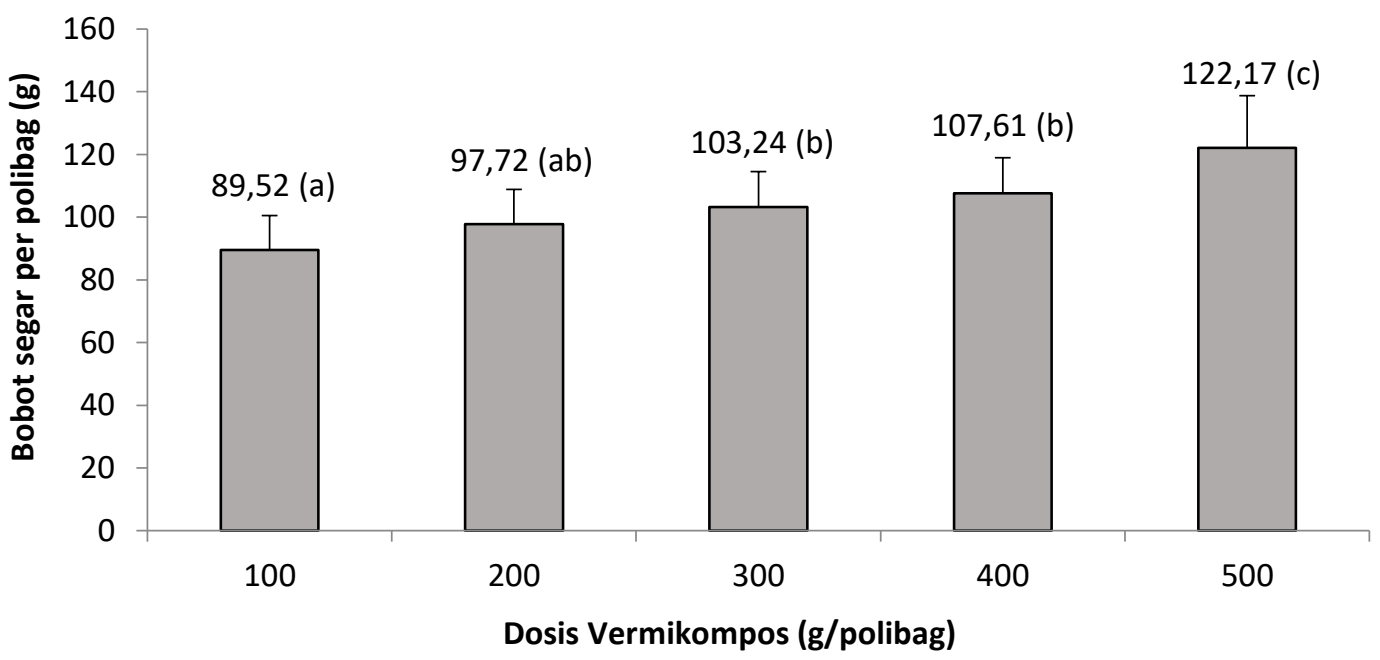

Gambar 2. Pengaruh dosis vermikompos terhadap bobot segar kangkung per polibag (g) 
Hasil uji Dunnet 5\% (Tabel 3) menunjukkan pada parameter bobot segar biomassa per tanaman beberapa perlakuan kombinasi metode dan dosis aplikasi vermikompos tidak berbeda nyata dengan kontrol kecuali pada perlakuan aplikasi vermikompos padat dengan dosis $500 \mathrm{~g} /$ polibag, kombinasi vermikompos padat $250 \mathrm{~g} /$ polibag dan $250 \mathrm{~g} /$ polibag vermikompos cair dan vermikompos cair $500 \mathrm{~g} /$ polibag yang menunjukkan hasil yang lebih tinggi dibandingkan dengan kontrol (perlakuan pupuk anorganik). Bobot segar biomassa per polibag pada perlakuan kombinasi metode dan dosis aplikasi vermikompos sebagian besar memberikan hasil yang lebih tinggi secara nyata dibandingkan dengan kontrol kecuali pada perlakuan vermikompos padat dengan dosis $100 \mathrm{~g} /$ polibag, kombinasi Vermikompos padat $50 \mathrm{~g} /$ polibag dan $50 \mathrm{~g} /$ polibag vermikompos cair, kombinasi vermikompos padat $100 \mathrm{~g} /$ polibag dan 100 $\mathrm{g} /$ polibag vermikompos cair, vermikompos cair 100 $\mathrm{g} /$ polibag dan vermikompos cair $200 \mathrm{~g} /$ polibag.

Tabel 3. Hasil uji Dunnet $5 \%$ rata-rata bobot segar pada perlakuan metode aplikasi dan dosis vermikompos dibandingkan dengan kontrol

\begin{tabular}{llll}
\hline \multicolumn{2}{c}{ Perlakuan } & $\begin{array}{l}\text { Bobot Segar } \\
\text { per tanaman } \\
(\mathrm{g})\end{array}$ & $\begin{array}{l}\text { Bobot Segar } \\
\text { per polibag } \\
(\mathrm{g})\end{array}$ \\
\hline $\begin{array}{l}\text { Mermikompos } \\
\text { Kontrol }\end{array}$ & Dosis & 12,05 & 88,99 \\
\hline \multirow{4}{*}{ Padat } & 100 & $7,93^{\#}$ & $97,76^{\text {tn }}$ \\
& 200 & $10,30^{\#}$ & $102,71^{*}$ \\
& 300 & $10,28^{\#}$ & $105,94^{*}$ \\
& 400 & $12,26^{\text {tn }}$ & $110,05^{*}$ \\
Padat dan & 500 & $13,63^{*}$ & $120,25^{*}$ \\
Cair & 100 & $7,68^{\#}$ & $85,88^{\text {tn }}$ \\
& 200 & $8,94^{\#}$ & $94,91^{\text {tn }}$ \\
& 300 & $10,15^{\#}$ & $102,49^{*}$ \\
& 400 & $10,78^{\#}$ & $109,46^{*}$ \\
Cair & 500 & $13,84^{*}$ & $122,04^{*}$ \\
& 100 & $8,30^{\#}$ & $84,92^{\text {tn }}$ \\
& 200 & $9,65^{\#}$ & $95,53^{\text {tn }}$ \\
& 300 & $10,47^{\#}$ & $101,30^{*}$ \\
\hline Dunnet 5\% & 400 & $11,18^{\text {tn }}$ & $103,33^{*}$ \\
\hline
\end{tabular}

Keterangan: tanda * menunjukkan berbeda nyata lebih besar dari kontrol, tanda \# menunjukkan berbeda nyata lebih kecil dari kontrol, tn menunjukkan tidak berbeda nyata dengan kontrol.

Hasil penelitian ini memperlihatkan keunggulan penggunaan vermikompos dibandingkan dengan pupuk anorganik. Vermikompos memiliki sejumlah keuntungan dalam budidaya tanaman, khususnya pada budidaya tanaman tanpa menggunakan tanah karena vermikompos mampu menyerap dan menyimpan air pada media yang terlalu porus sebagaimana dalam media hidroponik dimana fungsi media tumbuh dalam sistem hidroponik adalah untuk menyediakan oksigen bagi akar tanaman dan menopang berdirinya tanaman (Kaei-Kazzaz dan El-Kazzaz 2017). Vermikompos mengandung mikroorganisme dalam jumlah yang tinggi, sehingga meningkatkan aktivitas mikroorganisme yang menguntungkan bagi tanaman (Sallaku et al. 2009). Selain itu vermikompos mengandung nutrisi yang dibutuhkan oleh tanaman dalam bentuk nitrat, fosfat, kalsium dan potasium yang mudah larut (Azarmi et al. 2008).

Hasil analisis uji BNJ 5\% dan uji Dunnet kombinasi perlakukan metode dan dosis aplikasi vermikompos menunjukkan bahwa perlakuan aplikasi vermikompos padat dengan dosis $500 \mathrm{~g} /$ polibag memiliki kandungan Klorofil A tertinggi namun tidak berbeda nyata dengan perlakuan aplikasi vermikompos cair dengan dosis 400 g/polibag, sedangkan pada Klorofil B rata-rata tertinggi pada perlakuan aplikasi vermikompos padat dengan dosis $500 \mathrm{~g} /$ polibag dan berbeda nyata dengan semua perlakuan (Tabel 4).

Tabel 4. Hasil uji BNJ $5 \%$ dan Dunnet $5 \%$ rata-rata kandungan klorofil tanaman kangkung $(\mu \mathrm{g} / \mathrm{ml})$ pada perlakuan metode aplikasi dan dosis vermikompos

\begin{tabular}{|c|c|c|c|}
\hline \multicolumn{2}{|c|}{ Perlakuan } & \multirow[b]{2}{*}{ Klorofil A } & \multirow[b]{2}{*}{ Klorofil E } \\
\hline $\begin{array}{l}\text { Metode Aplikasi } \\
\text { Vermikompos }\end{array}$ & Dosis & & \\
\hline Kontrol & & 28,75 & 26,73 \\
\hline \multirow{5}{*}{ Padat } & 100 & $22,49 a b$ \# & $27,05 a^{\text {tn }}$ \\
\hline & 200 & $23,70 a b$ \# & $25,90 a^{\text {tn }}$ \\
\hline & 300 & $25,29 b^{\#}$ & $32,65 b$ * \\
\hline & 400 & $25,99 b^{\#}$ & $34,08 \mathrm{~b}$ * \\
\hline & 500 & $30,10 c^{\text {tn }}$ & $54,79 c^{*}$ \\
\hline \multirow{5}{*}{ Padat dan Cair } & 100 & $20,95 a^{\#}$ & $22,78 a^{\text {tn }}$ \\
\hline & 200 & $22,17 a b^{\#}$ & $25,80 a^{\text {tn }}$ \\
\hline & 300 & $22,66 a b$ \# & $29,71 a^{\text {tn }}$ \\
\hline & 400 & $24,58 b^{\#}$ & $35,48 b^{*}$ \\
\hline & 500 & $26,34 b^{\#}$ & $38,03 b^{*}$ \\
\hline \multirow{5}{*}{ Cair } & 100 & $21,61 a b$ \# & $27,08 a^{\text {tn }}$ \\
\hline & 200 & $26,68 b^{\#}$ & $25,73 a^{\text {tn }}$ \\
\hline & 300 & $26,36 b^{\#}$ & $30,37 a^{\text {tn }}$ \\
\hline & 400 & 27,06 bc \# & $32,99 \mathrm{~b}$ * \\
\hline & 500 & $26,20 b^{\#}$ & $39,44 b^{*}$ \\
\hline BNJ $5 \%$ & & 2,84 & 8,62 \\
\hline Dunnet 5\% & & 1,32 & 4,00 \\
\hline
\end{tabular}

Keterangan: angka yang diikuti dengan huruf yang sama pada kolom yang sama menunjukkan tidak berbeda nyata pada uji BNJ taraf $5 \%$, tanda * menunjukkan berbeda nyata lebih besar dari kontrol, tanda \# berbeda nyata lebih kecil dari kontrol, tn menunjukkan tidak berbeda nyata dengan kontrol.

Hasil uji Dunnet 5\% (Tabel 4) menunjukkan bahwa kombinasi perlakuan metode dan dosis aplikasi vermikompos pada klorofil $A$ memberikan hasil yang lebih kecil dibandingkan dengan kontrol $(P<0,05)$ pada semua perlakuan kecuali perlakuan aplikasi vermikompos padat dengan dosis $500 \mathrm{~g} /$ polibag memberikan hasil yang tidak berbeda nyata dengan kontrol. Sedangkan pada klorofil B menunjukkan hasil yang berbeda nyata dengan kontrol pada perlakuan aplikasi vermikompos padat dengan dosis $300 \mathrm{~g} /$ polibag, aplikasi vermikompos padat dengan dosis $400 \mathrm{~g} /$ polibag, 
aplikasi vermikompos padat dengan dosis $500 \mathrm{~g} / \mathrm{polibag}$, kombinasi vermikompos padat $200 \mathrm{~g} /$ polibag dan 200 g/polibag vermikompos cair, kombinasi vermikompos padat $250 \mathrm{~g} /$ polibag dan $250 \mathrm{~g} /$ polibag vermikompos cair, vermikompos cair $400 \mathrm{~g} /$ polibag) dan vermikompos cair $500 \mathrm{~g} /$ polibag.

Hasil analisis kandungan klorofil secara umum menunjukkan bahwa hasil yang tertinggi terdapat pada aplikasi vermikompos padat pada dosis aplikasi yang $500 \mathrm{~g} /$ polibag. Hal ini menunjukkan bahwa suplai hara yang cukup akan meningkatkan pembentukan klorofil tanaman. Klorofil merupakan suatu jaringan yang terdiri atas atom $\mathrm{C}, \mathrm{H}, \mathrm{N}$, dan $\mathrm{O}$ yang mengelilingi atom tunggal Mg. Klorofil menangkap kekuatan hidup atau energi matahari dan digunakan untuk membelah molekul $\mathrm{H}_{2} \mathrm{O}$ menjadi unsur $\mathrm{H}$ dan $\mathrm{O}_{2}$, kemudian menggabungkan antara unsur $\mathrm{H}$ dan gas $\mathrm{CO}_{2}$ dan dihasilkan gula tumbuhan atau karbohidrat. Klorofil terdapat di dalam kloroplas (Wirosaputro dan Sumartini 2016). Tumburu et al. (2017) menambahkan bahwa klorofil merupakan unit dasar sistem energi tanaman selama proses fotosintesis. Selain kualitas cahaya, produksi dan aktivitas klorofil dipengaruhi oleh nutrisi mineral dan metabolit kimia yang diproduksi dalam sistem tanaman.

Kandungan klorofil yang tinggi menunjukkan kualitas kangkung yang ditanam pada media hidroganik menggunakan vermikompos lebih tinggi dibandingkan dengan kontrol yang menggunakan pupuk anorganik (Tabel 4). Lordan et al. (2011) melaporkan bahwa klorofil bermanfaat bagi kesehatan manusia, karena Klorofil dapat menetralkan senyawa hidrofobik karsinogenik, seperti hidrokarbon aromatik polisiklik, amina heterosiklik, dan aflatoksin, dengan cara mengikatnya, sehingga tidak membahayakan bagi kesehatan manusia. Semakin tinggi kandungan klorofil sayursayuran, semakin baik kualitasnya sebagai pangan fungsional. Dengan demikian aplikasi vermikompos mampu meningkatkan kualitas kangkung karena kandungan klorofilnya lebih tinggi dibandingkan kontrol yang menggunakan pupuk anorganik.

\section{KESIMPULAN DAN SARAN}

Berdasarkan hasil penelitian ini dapat disimpulkan aplikasi vermikompos $500 \mathrm{~g} /$ polibag memberikan hasil kangkung yang tertinggi pada tiap-tiap metode aplikasi vermikompos.. Kandungan klorofil tanaman kangkung tertinggi sebesar 30,10 $\mathrm{gg} / \mathrm{ml}$ (klorofil a) dan 54,79 $\mathrm{\mu g} / \mathrm{ml}$ (klorofil b) ditemukan pada aplikasi vermikompos padat dengan dosis $500 \mathrm{~g} /$ polibag. Hasil ini menyarankan bahwa untuk meningkatkan hasil dan kualitas tanaman kangkung secara hidroganik perlu diaplikasikan vermikompos padat dengan dosis $500 \mathrm{~g} /$ polibag.

\section{UCAPAN TERIMAKASIH}

Penulis mengucapkan terima kasih kepada DRPM Dikti yang telah mendanai penelitian ini dalam skema PTUPT tahun anggaran 2019 serta kepala laboratorium Agroteknologi yang memberikan fasilitas penggunaan laboratorium kompos, laboratorium terpadu dan rumah plastik selama penelitian berlangsung serta semua pihak yang turut memberikan kontribusi finansial untuk pelaksanaan penelitian ini.

\section{DAFTAR PUSTAKA}

Atiyeh RM, Domínguez J, Subler S, Edwards CA. 2000. Changes in biochemical properties of cow manure during processing by earthworms (Eisenia andrei, Bouché) and the effects on seedling growth. Pedobiologia (Jena). 44(6):709-724. doi: 10.1078/S0031-4056(04)70084-0.

Azarmi R, Giglou MT, Taleshmikail RD. 2008. Influence of vermicompost on soil chemical and physical properties in tomato (Lycopersicum esculentum) field. African J Biotechnol. 7(14):2397-2401.

Bachman GR, Metzger JD. 2007. Physical and Chemical Characteristics of a Commercial Potting Substrate Amended with Vermicompost Produced from Two Different Manure Sources. HortTechnology hortte. 17(3):336-340. doi:10.21273/HORTTECH.17.3.336.

Biederman LA, Harpole WS. 2013. Biochar and its effects on plant productivity and nutrient cycling: a meta-analysis. GCB Bioenergy. 5(2):202-214. doi:10.1111/gcbb.12037.

Bulgari R, Baldi A, Ferrante A, Lenzi A. 2017. Yield and quality of basil, Swiss chard, and rocket microgreens grown in a hydroponic system. New Zeal J Crop Hortic Sci. 45(2):119-129.

Grigatti M, Giorgioni ME, Ciavatta C. 2007. Compostbased growing media: influence on growth and nutrient use of bedding plants. Bioresour Technol. 98(18):3526-34. doi: 10.1016/j.biortech.2006.11.016.

Irawan B, Ariningsih E. 2014. Agribisnis Sayuran dan Buah: Peluang Pasar, Dinamika Produksi dan Strategi Peningkatan Daya Saing. In: Haryono, editor. Memperkuat Daya Saing Produk Pertanian. Jakarta: IAARD Press. p. 147-176.

Kaei-Kazzaz, El-Kazzaz A. 2017. Soilless Agriculture a New and Advanced Method for Agriculture Development: An Introduction. Agric Res Technol Access J. 3(2):63-72. doi: 10.19080/ARTOAJ.2017.03.555610.

Kaushik P, Garg VK. 2003. Vermicomposting of mixed solid textile mill sludge and cow dung with the epigeic earthworm Eisenia foetida. Bioresour Technol. 90(3):311-6. doi:10.1016/s0960-8524(03)00146-9.

Khan FA. 2018. A Review a Hydroponic Greenhouse Cultivation for Sustainable Agriculture. Int J Agric Environ Food Sci. 2(2):59-66. doi:10.31015/jaefs.18010.

Lazcano C, Arnold J, Tato A, Zaller JG, Domínguez J. 2009. Compost and vermicompost as nursery pot components: effects on tomato plant growth and morphology. Spanish J Agric Res. 7(4):944-951. doi:10.5424/sjar/2009074-1107.

Lazcano C, Domínguez J. 2011. The use of vermicompost in sustainable agriculture: impact on plant growth and soil fertility. In: Mohammad Miransari, editor. Soil nutrients. Vol. 10. Nova Science Publishers New York, NY. p. 187. 
Liang B, Lehmann J, Solomon D, Kinyangi J, Grossman J, O'Neill B, Skjemstad JO, Thies J, Luizão FJ, Petersen J, et al. 2006. Black Carbon Increases Cation Exchange Capacity in Soils. Soil Sci Soc Am J. 70(5):1719-1730. doi:10.2136/sssaj2005.0383.

Lingga P. 2006. Hidroponik Bercocok Tanam tanpa Tanah. Jakarta: Penebar Swadaya.

Lordan S, Ross RP, Stanton C. 2011. Marine bioactives as functional food ingredients: potential to reduce the incidence of chronic diseases. Mar Drugs. 9(6):1056100. doi:10.3390/md9061056.

Marsono, Sigit P. 2001. Pupuk Akar, Jenis Dan Aplikasinya. Jakarta: Penebar Swadaya.

Nurhidayati, Machfudz M, Murwani I. 2017a. Pertumbuhan, Hasil dan Kualitas Tanaman Brokoli (Brassica oleraceae L.) Sebagai Respon Terhadap Aplikasi Tiga Macam Vermikompos dengan Sistem Penanaman Secara Organik. In: Prosiding. Seminar Nasional. Fakultas Pertanian Universitas Nasional Jakarta. Vol. 8.

Nurhidayati, Machfudz M, Murwani I. 2017b. Direct and Residual Effect of Various Vermicomposton Yield and Qualityof Broccoli. J Appl Sci Res. 13(8):30-37.

Nurhidayati, Machfudz M, Murwani I. 2018. Direct and residual effect of various vermicompost on soil nutrient and nutrient uptake dynamics and productivity of four mustard Pak-Coi (Brassica rapa L.) sequences in organic farming system. Int J Recycl Org Waste Agric. 7(2):173-181. doi:10.1007/s40093018-0203-0.

Nurhidayati N, Ali U, Murwani I. 2016. Yield and Quality of Cabbage (Brassica oleracea L. var. Capitata) Under Organic Growing Media Using Vermicompost and Earthworm Pontoscolex corethrurus Inoculation. Agric Agric Sci Procedia. 11:5-13. doi: 10.1016/j.aaspro.2016.12.002.

Nurhidayati, Usman A, Murwani I. 2015. Influence of the kind of vermicompost material and earthworm Pontoscolex corethrurus population on the yield and quality of phak-coi mustard (Brassica rapa L.) with organic potting media. In: Proceeding of the first international conference on life science and biotechnology exploration and conservation of biodiversity. p. 168-176.

Pant A, Radovich TJK, Hue NV, Arancon NQ. 2011. Effects of Vermicompost Tea (Aqueous Extract) on Pak Choi Yield, Quality, and on Soil Biological Properties. Compost Sci Util. 19(4):279-292. doi:10.1080/1065657X.2011.10737010.
Papafotiou M, Kargas G, Lytra I. 2005. Olive-mill Waste Compost as a Growth Medium Component for Foliage Potted Plants. HortScience. 40(6):1746-1750. doi: 10.21273/HORTSCI.40.6.1746.

Pracaya. 2009. Bertanam Sayur Organik. Jakarta: Penebar Swadaya.

Razzaghifard SA, Gholipouri A, Tobeh A, Reza mousavi meshkini S. 2017. Effect of mycorrhiza, vermicompost and nanofertilizer on quantitative and qualitative characteristics of Cucurbita pepo L. Eur J Hortic Sci. 82(2):105-114. doi:10.17660/eJHS.2017/82.2.6.

Resh HM. 2012. Hydroponic food production: a definitive guidebook for the advanced home gardener and the commercial hydroponic grower. 7th ed. Boca Raton, FL: CRC Press.

Sallaku G, Babaj I, Kaciu S, Balliu A. 2009. The influence of vermicompost on plant growth characteristics of cucumber (Cucumis sativus L.) seedlings under saline conditions. J Food, Agric Environ. 7(3\&4):869872.

Sani B. 2015. Hidroponik. Jakarta: Penebar Swadaya.

Sengupta A, Banerjee H. 2012. Soil-less culture in modern agriculture. World J Sci Technol. 2(7):103108.

Sharma N, Acharya S, Kumar K, Singh N, Chaurasia OP. 2018. Hydroponics as an advanced technique for vegetable production: An overview. J Soil Water Conserv. 17(4):364. doi:10.5958/24557145.2018.00056.5.

Singh U, Giller KE, Palm CA, Ladha JK, Breman H. 2001. Synchronizing $\mathrm{N}$ Release from Organic Residues: Opportunities for Integrated Management of $\mathrm{N}$. Wisniewski J, editor. Sci World J. 1:880-886. doi:10.1100/tsw.2001.361.

Tumburu L, Andersen CP, Rygiewicz PT, Reichman JR. 2017. Molecular and physiological responses to titanium dioxide and cerium oxide nanoparticles in Arabidopsis. Environ Toxicol Chem. 36(1):71-82. doi:10.1002/etc.3500.

Wintermans JFGM, De Mots A. 1965. Spectrophotometric characteristics of chlorophylls a and $b$ and their phenophytins in ethanol. Biochim Biophys Acta - Biophys Incl Photosynth. 109(2):448453. doi:10.1016/0926-6585(65)90170-6.

Wirosaputro S, Sumartini T. 2016. Chlorella: makanan kesehatan global alami. UGM PRESS. 